\section{Alcohol use disorder and depression: proposed rewording of Choosing Wisely recommendation}

This letter is in response to a specific recommendation of the Choosing Wisely campaign. ${ }^{1}$ The following is a direct quote:

Don't routinely prescribe antidepressants as firstline treatment for depression comorbid with an active alcohol use disorder without first considering the possibility of a period of sobriety and subsequent reassessment for the persistence of depressive symptoms. ${ }^{2}$

As addiction psychiatrists in Canada, we are concerned that this blanket statement may have a substantial impact on the treatment of patients with alcohol use disorder who have a major depressive disorder. That people can stop drinking, and consequently, any depressive symptoms will resolve is a simplistic view. There is evidence that depressive symptoms resolve with alcohol cessation, but getting those with addiction to abstain is easier said than done. Alcohol use disorder is notable in our society (lifetime prevalence of $29.1 \%$ ) and is associated with major depressive disorder (adjusted odds ratio [AOR] 1.3, 95\% confidence interval [Cl] 1.15-1.39) and all other mood disorders (AOR 1.5, 95\% Cl 1.37-1.63), even with adjustments in sociodemographic characteristics and in other psychiatric disorders. ${ }^{3}$ Patients with depression and alcohol use disorder are at higher risk of suicide attempts, ${ }^{4}$ and not treating their depression may have deleterious effects, especially in the elderly. ${ }^{5}$

Guidelines affect physician practises, ${ }^{6}$ and this Choosing Wisely recommendation could lead to primary care physicians not treating patients with alcohol use disorders.

This is very concerning, given that so many people with substance use disorder do not seek help. ${ }^{7}$ If patients do reach out for help for depressive symptoms, being told that they need to be sober before they can be treated could be invalidating, which would be a barrier to treatment.
Patients with alcohol use disorder are sometimes stigmatized by health professionals, which can contribute to suboptimal health care..$^{8,9} \mathrm{~A}$ recommendation to not treat patients' depressive symptoms could further stigmatize them.

The research around the treatment of alcohol use disorder with comorbid depression is still inconclusive: a recent metaanalysis ${ }^{10}$ showed that depression treatment in alcohol use disorder had large early improvement in depressive symptoms. A randomized controlled trial showed that the combination of sertraline and naltrexone was superior to either alone for achieving abstinence, reducing heavy drinking and improving mood. ${ }^{11}$ Adamson and colleagues ${ }^{12}$ found no benefit in combining citalopram with naltrexone. Charney and Heath ${ }^{13}$ found poorer outcomes with citalopram treatment in alcohol dependence. This inconclusive and conflicting evidence makes it impossible to make a recommendation. It is interesting that citalopram is also associated with poorer outcomes in posttraumatic stress disorder (PTSD) literature and is not recommended in PTSD treatment guidelines. ${ }^{14}$ One could likely recommend against the use of citalopram, based on the current evidence.

As described by Nunes and Levin, antidepressant efficacy in alcohol use disorder varies depending on placebo effects. Studies with high placebo response show little to no effect and studies with low placebo response show a moderate to strong effect. ${ }^{15}$

We propose that the Choosing Wisely statement be reworded. This is important because the Province of Alberta has accepted the Choosing Wisely campaign as a guideline for physicians in Alberta. The following is our recommendation:

In substance treatment, do not routinely prescribe antidepressants as first-line treatment for depression comorbid with an active alcohol use disorder without first considering the possibility of a period of abstinence of two to four weeks and subsequent reassessment for the persistence of depressive symptoms.

The American Society of Addictions Medicine specifically recommends treating the depressive disorder, first-line being psy- chotherapy, and for more severe symptoms, following the Texas Medication Algorithm for antidepressant treatment. ${ }^{16}$ The International Society of Addictions Medicine, the Canadian standard of care for addiction medicine, suggests treating the substance use disorder first and if depression continues, then treat. ${ }^{17}$ The goal of primary care is to start with a brief intervention, then attempt to have the patient become involved in treatment for alcohol use disorder.

Specifically, treatment is a biopsychosocial-spiritual approach that includes detoxification, anticraving medications and psychosocial interventions, along with comorbid treatment of psychiatric illnesses.

Unfortunately, the blanket statement by Choosing Wisely could have deleterious effects on those with alcohol use disorder, is not evidence-based, could lead to less access to care, and could increase stigma against patients with alcohol use disorder and major depressive disorder or depressive symptoms. The treatment of patients with addictions and mental health problems should focus on reducing stigma and increasing assess to care.

\section{Robert L. Tanguay MD}

Clinical Lecturer, Department of Psychiatry; Pain Medicine Fellow, Department of Anesthesia, University of Calgary; Psychiatric and Addictions Medicine Consultant, Calgary Chronic Pain Centre; Psychiatric Consultant, Opioid Dependence Program Group Therapist, Dialectical Behavioural Therapy Program, Calgary, Alta.

\section{Wiplove Lamba MD}

Addiction Physician, St. Michael's Hospital Lecturer, Department of Psychiatry, University of Toronto, Toronto, Ont.

\section{Ronald Fraser MD}

Head, Inpatient Detoxication Services; Addictions Unit Director, Extended Care Borderline Personality Disorder Clinic; Health Centre Associate Professor, Department of Psychiatry, McGill University, Montréal, Que.; Dalhousie University, Halifax, NS 


\section{Phillip Mills MB MMSP}

Assistant Professor, Department of Psychiatry, Dalhousie University, Halifax, NS; Clinical Academic Leader, Addictions Program, Nova Scotia Hospital,

Dartmouth, NS

\section{Ataa Azarbar MD MSc}

Addiction Psychiatrist, Burnaby Centre for Mental Health and Addictions, Burnaby,

BC; Clinical Instructor, University of

British Columbia, Vancouver, BC

Nady el-Guebaly MD

Professor and Head, Division of Addiction, Department of Psychiatry, University of Calgary; Research Director, Alberta Gambling Research Institute, Calgary, Alta.; Consulting Psychiatrist, Alberta Health Services, Edmonton, Alta.

Cite as: CMAJ 2017 March 20;189:E442-3. doi: $10.1503 / \mathrm{cmaj} .732873$

\section{References}

1. Levinson W, Huynh T. Engaging physicians and patients in conversations about unnecessary tests and procedures: Choosing Wisely Canada. CMAJ 2014; 186: 325-6.

2. Psychiatry: thirteen things physicians and patients should question. Toronto: Choosing Wisely Can- ada; 2015. Available: www.choosingwiselycanada. org/recommendations/psychiatry/ (accessed 2017 Jan. 30)

3. Grant BF, Goldstein RB, Saha TD, et al. Epidemiology of DSM-5 alcohol use disorder: results from the National Epidemiological Survey on Alcohol and Related Conditions III. JAMA Psychiatry 2015;72:757-66.

4. Brière FN, Rohde P, Seeley JR, et al. Comorbidity between major depressive disorder and alcohol use disorder from adolescence to adulthood. Compr Psychiatry 2014;55:526-33.

5. Morin J, Wiktorsson S, Marlow T, et al. Alcohol use disorder in elderly suicide attempters: a comparison study. Am J Geriatr Psychiatry 2013;21:196-203.

6. Grol R, Dalhuijsen J, Thomas S, et al. Attributes of clinical guidelines that influence use of guidelines in general practice: observational study. BMJ 1998;317:858-61.

7. Addiction medicine: closing the gap between science and practice. New York: The National Center of Addiction and Substance Abuse; 2012.

8. van Boekel LC, Brouwers EPM, van Weeghel J, et al. Stigma among health professionals towards patients with substance use disorders and its consequences for healthcare delivery: systematic review. Drug Alcohol Depend 2013;131:23-35.

9. van Boekel LC, Brouwers EPM, van Weeghel J, et al. Inequalities in healthcare provision for individuals with substance use disorders: perspectives from healthcare professionals and clients. J Subst Use 2016;21:133-40.

10. Foulds JA, Adamson SJ, Boden JM, et al. Depression in patients with alcohol use disorders: systematic review and meta-analysis of outcomes for independent and substance-induced disorders. J Affect Disord 2015;185:47-59.
11. Pettinati HM, Oslin DW, Kampman KM, et al. A double-blind, placebo-controlled trial combining sertraline and naltrexone for treating co-occurring depression and alcohol dependence. Am J Psychiatry 2010;167:668-75.

12. Adamson SJ, Sellman JD, Foulds JA, et al. A randomized trial of combined citalopram and naltrexone for nonabstinent outpatients with co-occurring alcohol dependence and major depression. J Clin Psychopharmacol 2015; 35:143-9.

13. Charney DA, Heath LM, Zikos E, et al. Poorer outcomes with citalopram treatment for alcohol dependence: a randomized, double-blind, placebocontrolled trial. Alcohol Clin Exp Res 2015;39:1756-65.

14. Katzman MA, Bleau P, Chokka P, et al. Canadian Anxiety Guidelines Initiative Group on behalf of the Anxiety Disorders Association of Canada/ Association Canadienne des troubles anxieux and McGill University. Canadian clinical practice guidelines for the management of anxiety, posttraumatic stress and obsessivecompulsive disorders. BMC Psychiatry 2014; 14(Suppl 1):S1.

15. Nunes EV, Levin FR. Treatment of depression in patients with alcohol or other drug dependence: a meta-analysis. JAMA 2004;291:1887-96.

16. Ries RK, Fiellin DA, Miller SC, et al., editors. The ASAM principles of addiction medicine. 5th ed. Philadelphia: Wolters Kluwer Health; 2014.

17. el-Guebaly N, Carra G, Galanter M, editors. Textbook of addiction treatment: international perspectives. 1st ed. Milan (Italy): Springer-Verlag Mailand; 2015.

Competing interests: None declared. 